\title{
Alterations in the Metabolism of Carbohydrates in Hypertensives Treated with Atenolol
}

\author{
Adalberto Fortún Prieto* \\ Specialist in Internal Medicine, University of Medical Sciences of Pinar del Río, Cuba
}

Submission: November 03, 2019; Published: November 14, 2019

*Corresponding author: Adalberto Fortún Prieto, $1^{\text {st }} \& 2^{\text {nd }}$ Degree Specialist in Internal Medicine, 2nd Degree Specialist in Hematology, Assistant Professor and Consultant, Assistant Investigator, Master's Degree in Satisfactory Longevity and Medical Education, University of Medical Sciences of Pinar del Río, Cuba

\begin{abstract}
Beta-blockers have been used for decades in the treatment of high blood pressure and among them, atenolol continúto being a relatively common option. Among its side effects is the alteration in carbohydrate metabolism, which is currently considered an obstacle to its systematic use. We conducted a study with 50 patients who use this drug as a single therapy to identify alterations in glycaemic control in them. Fasting, immediate post-pandrial (30 minutes) and $1^{\text {st }}$ and $2^{\text {nd }}$ hours after glucose overload were determined. In no case was the presence of diabetes mellitus, however, in more than a third of them there were plasma blood glucose levels in the range of "glucose tolerance disorder" in samples taken fasting and post-pandrial immediately, while in the 1st and 2nd hour after gluco seoverload, significant levels of said "glucose tolerance disorder" were identified, which involves a potential risk protein glycosylation It is concluded that this metabolic disorder is very common in patients who use atenolol as a single drug in their treatment and that adequate attention to lifestyle modifications and dietary habits is probably necessary in patients who decide to indicate this drug as an anti-hypertensive drug.
\end{abstract}

Keywords: Metabolism of carbohydrates; Hypertensives; Atenolol; Glucose tolerance; Anti-hypertensive drug; Myocardial infarction; Catecholamines; Patients predominated; Post-pandrial; Microvascular damage

\section{Introduction}

Beta-blockers were considered an acceptable first-line therapy in hypertensive [1] patients and are still widely used due to their safety and efficacy in reducing mortality and morbidity, with atenolol being one of the most evaluated in studies on the effects of antihypertensives and the complications of their use. [2,3] In spite of this, doctors are generally subject to a group of indecisions and controversies which have so far not been adequately defined. The response to these disputes should ultimately contribute to the understanding of the antihypertensive effectiveness of treatment and its side effects, particularly on metabolic control, and the risk of the onset of diabetes as a result of its ortilization. Sand is known that beta-blockers reduce the risk of cardiovascular events when used as secondary prevention in patients who have already had a previous ischemic cardiovascular event (myocardial infarction) or congestive heart failure [4] ifn embargo, in recent years their use has been questioned. In the case ofatenolol, there has always been the criterion that adverse metabolic effects, particularly glycaemic control disorders, often occur [5]. There are recent communications about the disadvantages of the use of beta-blockers as a first-line drug in the treatment of high blood pressure [6-8] partly due to the increased risk of developing adverse metabolic effects on glucose, insulin and lipid levels, which makes it necessary to assess the magnitude of this problem and determine whether its use constitutes an element that clearly should be taken into account when deciding on the treatment of a patient with hypertension. Available data related to the role of beta-blockers in the management of high blood pressure often show confusion about their role in the therapeutic management of the disease $[7,9]$. Current evidence suggests that older betablockers may not be preferable as first-line drugs in the treatment of hypertensive patients, however, their use remains usual and new beta-blockers with vasodilator properties are used in the presence of uncontrolled or resistant hypertension, especially those young patients. [10]. Older beta-blockers, especially atenolol, have well-known adverse metabolic effects, particularly glycaemic control disorders. This adverse effect seems to occur only with beta-blockers that do not possess vasodilatory properties. It could be dependent on several factors, all with potential effect on carbohydrate metabolism, especially peripheral utilization of glucose. By blocking beta- 1 receptors, these drugs reduce cardiac output and blood pressure. [1-11] This group of drugs decreases the release of renin by the juxta taglo merular cells of the kidney by presynaptic blockage. [12] Other mechanisms such as reducing venous return, generating nitric oxide, reducing vasomotor tone associated with increased vascular adaptability and decreasing the 


\section{Global Journal of Reproductive Medicine}

presor response to catecholamines $[13,14]$ may also participate in the vasodilatory action of beta-blockers, which is associated with decreased performic response to catecholamines $[13,14]$ may also participate in the vasodilating action of beta-blockers, which is associated with decreased presurmise response to catecholamines $[13,14]$ may also participate in the vasodilating action of betablockers, which is associated with decreased presoramine response to catecholamines $[13,14]$ may also participate in the vasodilating action of beta-blockers, which is associated with decreased presoramine response to catecholamines $[13,14]$ may also participate in the vasodilating action of beta-blockers, which is associated with decreased presoramine response to catecholamines $[13,14]$ may also participate in the vasodilating action of beta- release of insulin and peripheral glucose utilization with the consequent tendency to hyperglycaemia. Treatment with beta-blockers results in an increased risk of diabetes mellitus debut compared to othernon-diuretic anti-hyper tensive agents [15].

As for the increased vascular risk, it should also be noted that the association of high blood pressure and diabetes is a risk factor predominantly of macrovascular type modifiable through dietary modifications, regular physical exercise, smoking cessation, adequate blood glucose level control and proper management of blood lipids, so the priority approach to the problem should be aimed at comprehensive management of the patient. There is consensus on the benefits of sympathetic blockers in patients with heart failure or acute myocardial infarction, including diabetics, however, in patients with uncomplicated high blood pressure the adverse metabolic effects are probably of greater relevance and have a greater chance of decreasing the advantageous effects than in other groups of patients [16]. It has not been clearly demonstrated whether glucose tolerance disorder occurs from

Result

Table 1: Gender and Age Distribution.

\begin{tabular}{|c|c|c|c|c|c|}
\hline Sex & Frequency & Average & Percentage & Minimum & Maximum (Years) \\
\hline Male & 33 & 66 & 47.6 & 21 & 60 \\
\hline Women's & 17 & 34 & 45.2 & 22 & 60 \\
\hline Total & 50 & 100 & 47.4 & 21 & 60 \\
\hline
\end{tabular}

Table 2: Results of Glycemic Profile Performed by Patients.

\begin{tabular}{|c|c|c|c|c|c|c|c|}
\hline \multicolumn{8}{|c|}{ Glucemia (mmol/l) } \\
\hline \multicolumn{8}{|c|}{ Fast 30 Minutes $1^{\text {st }}$ hour $2^{\text {nd }}$ hour } \\
\hline High & Normal (\%) & High & Normal (\%) & High & Normal (\%) & High & Normal (\%) \\
\hline 14 & $36(72 \%)$ & 14 & $36(72 \%)$ & 3 & $47(94 \%)$ & 8 & $42(84 \%)$ \\
\hline
\end{tabular}

Table 3: Overall Result of the Glycaemic Profile Performed.

\begin{tabular}{|c|c|c|c|c|}
\hline & $\begin{array}{c}\text { Theyunas } \\
\text { (Mmol/L) }\end{array}$ & $\begin{array}{c}\text { 30 minutes } \\
\text { (Mmol/L) }\end{array}$ & $\begin{array}{c}\text { 1st hour } \\
\text { (Mmol/L) }\end{array}$ & $\begin{array}{c}\text { 2nd hour } \\
\text { (Mmol/L) }\end{array}$ \\
\hline Media & 57,180 & 58,480 & 65,720 & 96,900 \\
\hline Median & 57,000 & 58,000 & 65,000 & 9.7 \\
\hline
\end{tabular}

As shown in Table 1 male patients predominated in thestudy, the average age was similar in both sexes, as well as the rest of the the immediate post-pandrial period, which could be another element involving vascular risk due to the protein glycosylation level involving [17]. or if these adverse effects of atenolol are related to with your blood concentration or those with elevated plasma levels of the drug have a higher chance of presenting this side effect. Based on these considerations regarding the metabolic risk of the use of beta-blocker drugsto $s$, we set out toassess whether the use of atenolol implies an increase in post-pandrial blood glucose levels, including immediate blood glucose, in order to identify a potential risk of hairor protein cosilation.

\section{Material and Methods}

A study was conducted in 50 hypertensive patients between 18 and 60 years of age admitted Hospital Surgical Surgical Lion Cuervo Rubio that use drum treatment with atenolol for a period of more than six months as the only anti-hypertensive therapy over a period of at least two years. Patients with diabetes mellitus and/ or dyslipidemia or who used diuretic treatment with thiazides were excluded. Patients were distributed according to age groups, sex. The clinical history has been seen from the medical history for fasting blood glucose, creatinine, cholesterol and triglycerides in the serum to learn about the presence of diabetes, renal function disorder or lipid profile alterations as comorbidity in each of the patients studied. She performed determination of fasting plasma glycaemia, at 30 minutes, as well as one hour and two hours after glucose overload with 82 gr of anhydrous glucose in 300 $\mathrm{ml}$ of water, using the usual clinical laboratory technique. For an alteration in fasting blood glucose values, at 30 minutes and 1 and 2 hours after glucose overload, values established in 2014 by the American Diabetes Association [18] were used, which uses as normal reference values $5.5 \mathrm{mmol} / \mathrm{L}$ for the sample obtained on the fasting and 30 minutes after the overload, $6.1 \mathrm{mmol} / \mathrm{L}$ after one hour and $9.0 \mathrm{mmol} / \mathrm{L}$ at two hours after the overload. statistical variables applied. Table 2 shows the result of the blood glucose determined in the four samples established according to the study design, finding that according to the baselines used, most patients showed elevation of fasting figures, as well as in each of the determinations made, with a predominance during the first hour after glucose overload .As shown in Table 3, the mean and median blood glucose figures obtained in the patients showed that 


\section{Global Journal of Reproductive Medicine}

in the four samples performed they were above those considered to be normal which shows a constant elevation of them.

\section{Discussion}

The exact mechanism through which beta-blockers increase glecalin levelsis uncertain, but because blocking of beta- 2 adrenergic receptors reduces insulin production in response to glucose, this is the most accepted explanation [19]. The existence of a risk of glucose tolerance disorder or the debut of diabetes mellitus associated with the use of atenolol [20]is known, however, the identification of immediate post-pandrial hyperglycemia (at 30 minutes) is not usually identified by conventional studies for the definition of these disorders and their identification may be a criterion that increases our understanding of the benefits or risks of frequent use of this drug in the treatment of high blood pressure. This pharmacological group, which remains widely used, remains preferred in hypertensives who have suffered myocardial infarction or heart failure from systolicdys function, but not in patients without comorbidities [21]. While the use of these drugs is usually avoided in patients with asthma or bronchial hyperreactivity, knowledge about the metabolic alterations they produce, in particular about glycaemic control and diabetes debut, has generated controversy. The frequency of the occurrence of diabetes associated with treatment with traditional beta-blockers is variable, however, when compared tothe use of thiazide diuretics, it is evident that they produce diabetes and glycaemic control disorders with a frequency $26 \%$ lower than [13] and when compared to the use of calcium channel blockers or angiotensinconverting enzyme inhibitors or its receptor, the risk of diabetes debut is higher by 21 and $23 \%$ respectively [22]. Vasodilator beta-blockers such as carvedilol and nebivolol, meanwhile, have shown a neutral or beneficial effect on metabolic parameters in patients with diabetes and hypertension [23]. and have even been reported to produce a decrease in glycosylated hemoglobin (HBA1c) associated with significant decrease in basal glycaemia and immediate post-pandrial [24]. In our study we evaluated 50 patients with high blood pressure who used atenolol as a unique drug for the treatment of their disease. Although there was a predominance of male patients, the average age in both sexes was similar; obesity was only present in one of the individuals evaluated, so its presence was not a determining factor for glycemic control alterations found in both groups. Results of the determination of fasting and immediate post-pandrial blood glucose figures (30 minutes), as well as in the 1 st and 2 nd hours after carbohydrate overload showed that in the four determinations they were above the figures considered to be "normal" according to the parameters that define the existence of a glucose tolerance disorder. It should be noted that blood glucose figures in the 1st and 2nd hours after overload were high in 94 and $84 \%$ of patients respectively, which shows their high presence in patients using atenolol as a single treatment for their hypertensive disease.

The analysis of the mean and median blood glucose figures in the four samples determined in each patient, increased than normal reference values, indicating the presence of glucose tolerance disorder as a frequent finding in this group of patients, and poses a potential risk of long-term vascular morbidity. It is known that a normal fasting and post-pandrial blood glucose figure immediately (30 minutes) should be $5.5 \mathrm{mmol} / \mathrm{L}(100$ $\mathrm{mg} / \mathrm{dl}$ ) [25], which ensures that the HBA1c level is maintained by $5.7 \%$ in the same way, individuals with blood glucose between 5.5 and $6 \mathrm{mmo} / \mathrm{L}(100$ and $125 \mathrm{mg} / \mathrm{dL})$ in fasting and immediate post-pandrial and those with values between 6.1 and $7 \mathrm{mmol} / \mathrm{L}$ (140 and $199 \mathrm{mg} / \mathrm{dL}$ ) have a risk between the 5-10\% higher for developing diabetes. It has been suggested that in this situation, proper lifestyle modification and dietary habits could reduce the risk of developing diabetes, which could reduce cardiovascular, renal, retinal and other complications, even in the presence of treatment with a beta-blocker.

There is sufficient evidence that microvascular complications of diabetes are associated with glycaemic control alterations that are detected in the tolerance test, including immediate postpadrial figure, even in the absence of defined diabetes, especially when the range found is found in the figures considered to be "glucose tolerance disorders" [26]. Our results indicate that the use of atenolol, a classic beta-blocker that is still frequently used as a single drug in the treatment of patients with hypertension, constitutes a risk of alternation of plasma blood glucose control. This side effect of this drug has been known for decades; however, the focus has been on assessing the appearance of defined diabetes and not so much the state of glucose intolerance, more frequent and equally risky. The alterations that occur on the control of blood glucose associated with the use of beta-blockers in hypertensive patients, may be within the range of "glucose tolerance disorder", even during the first 30 minutes after food ingestion, indicating that the risk to health is probably high, not only due to sustained protein glucosis implies, but also because of the risk of microvascular damage that results from this and that constitutes a determining element in the complications of this disease, which are also present in high blood pressure even in the absence of alterations in carbohydrate metabolism. Finally, it is necessary to evaluate whether an adequate change in dietary regimen, physical activity and elimination of other vascular risk factors, modify this trend in hypertensive patients who use atenolol as a single therapy of the disease.

\section{References}

1. Fernández Ferrer R A, Molina Hechavarría V (2011) Evaluation of treatment for the control of high blood pressure in an urban community. Medisan 15(1): 87.

2. Che Q, Schreiber M J, Rafey M A (2009) Beta-blockers for hypertension: Are they going out of style? Cleve Clin J Med 76(9): 533-542.

3. The Accord Study Group (2010) Effects of Intensive Blood-Pressure Control in Type 2 Diabetes Mellitus. N Engl J Med 362(17): 1575-1585.

4. López Nouel R L, Hurtado D, López Gómez L, Acosta Martínez J, Chazzin G, et al. (2014) An approach to knowing the prevalence of high blood pressure, cardiovascular risk factors and lifestyle in Venezuela. Cardiol Advances 34(2): 128-134. 


\section{Global Journal of Reproductive Medicine}

5. Sarafidis P A, Barkis G L (2006) Antihypertensive treatment with beta-blockers and the spectrum of glycaemic control. Q J Med 99(7): 431436.

6. Brunström M, Carlberg B (2016) Effect of antihypertensive treatment at different blood pressure levels in patients with diabetes mellitus: systematic review and meta-analyses. Br Med J 352: 717.

7. Weber M A, Schiffrin E L, White W B (2014) Clinical practice guidelines for the management of hypertension in the community a statement by the American Society of Hypertension and the International Society of Hypertension. J Clin Hypertens (Greenwich) 16(1): 14-26.

8. Blackburn DF, Lamb DA, Eurich DT, Johnson JA, Wilson TW, et al. (2007) Atenolol as initial antihypertensive therapy: an observational study comparing first-line agents. J Hypertens 25(7): 1499-1505.

9. Navare H A, Frye R F, Cooper-DeHoff R M, Shuster JJ, Hall K, et al. (2010) Atenolol Exposure and Risk for Development of Adverse Metabolic Effects: A Pilot Study. Pharmacotherapy 30(9): 872-878.

10. Johnson JA1, Boerwinkle E, Zineh I, Chapman AB, Bailey K, et al. (2009) Pharmacogenomics of antihypertensive drugs: rationale and design of the pharmacogenomic evaluation of antihypertensive responses (PEAR) study. Am Heart J 157(3): 442-449.

11. Brunström M, Carlberg B (2016) Effect of antihypertensive treatment at different blood pressure levels in patients with diabetes mellitus: systematic review and meta-analyses. BMJ 352.

12. Bangalore S, Fakheri R, Toklu B, Messerli F H (2016) Diabetes mellitus as a compelling indication for use of renin angiotensin system blockers: systematic review and meta-analysis of randomized trials. BM] 352. i438.

13. Holzgreve H, Nakov R, Beck K, Janka H U (2003) Antihy- pertensive therapy with verapamil SR plus trandol- april versus atenolol plus chlorthalidone on glycemic control. Am J Hypertens 16: 381-386.

14. Jensen M T, Andersen HU, Rossing P, Jensen J S (2016) Statins are independently associated with increased HbA1c in type 1 diabetes - The Thousand \& 1 Study Diabetes Res Clin Pract 111: 51-57.

15. Repaske D R (2016) Medication-induced diabetes mellitus. Pediatric Diabetes. 17(6): 392-327
16. Di Nicolantonio JJ, Fares H, Niazi A K, Chatterjee S, D Ascenzo F D, et al. (2015) $\beta$-Blockers in hypertension, diabetes, heart failure and acute myocardial infarction: a review of the literature. Open Heart 2(1): $\mathrm{e} 000230$.

17. Turnbull F, Neal B, Algert C (2005) Effects of different blood pressure-lowering regimens on major cardiovascular events in individuals with and without diabetes mellitus: results of prospectively designed overviews of randomized trials. Arch Intern Med 165(12): 1410-1419.

18. American Diabetes Association (2013) Diagnosis and classification of diabetes mellitus. Diabetes Care 36(1): S67-S74.

19. Iglesias R, Barutell L, Artola S, Serrano R (2014) Summary of the recommendations of the American Diabetes Association (ADA) 2014 for clinical practice in the management of diabetes mellitus Diabetes Practice 05(2):1-24

20. Reverte Cejudo D, Moreno Palomares JJ, Ferreira Pasos E M (1998) High blood pressure: update of your treatment. Inf Ter Sist Nac Health 22: 81-94.

21. Hirst J A, Farmer A J, Feakins B G, Aroson J K, Stevens R J (2015) Quantifying the effects of diuretics and $\beta$-adrenoceptor blockers on glycaemic control in diabetes mellitus - a systematic review and meta-analysis. Br J Clin Pharmacol 79(5): 733-743

22. Das D R, Routray S (2016) Treatment of Hypertension in 2016 - Role of Beta Blockers. IJSR - international journal of scientific research 5(1): 69.48.

23. Bakris B L, Fonseca V, Katholi R E, Mc Gill JB, Messerli F H, et al. (2004) Metabolic Effects of Carvedilol vs Metoprolol in Patients with Type 2 Diabetes Mellitus and Hypertension A Randomized Controlled Trial. JAMA 292(18): 2227-2235.

24. Akbar S, Alorainy M S (2014) The current status of beta blocker uses in the management of hypertension. Saudi Med J 35(11): 1307-1317.

25. (2006) Effect of rosiglitazone on the frequency of diabetes in patients with impaired glucose tolerance or impaired fasting glucose: a randomised controlled trial. The lancet 368(9541).

26. Wright A D, Barber S G, Kendall M J, Poole P H (1979) $\beta$-adrenoceptor-blocking drugs and blood sugar control in diabetes mellitus. $\mathrm{Br}$ Med J 1(6157): 159-161.

\section{Your next submission with Juniper Publishers will reach you the below assets}

- Quality Editorial service

- Swift Peer Review

- Reprints availability

- E-prints Service

- Manuscript Podcast for convenient understanding

- Global attainment for your research

- Manuscript accessibility in different formats

( Pdf, E-pub, Full Text, Audio)

- Unceasing customer service

Track the below URL for one-step submission

https://juniperpublishers.com/online-submission.php 